\title{
Neuroprotective expression of turmeric and curcumin
}

\author{
${ }^{1}$ Abbas, S., ${ }^{1}$ Latif, M.S., ${ }^{1}$ Shafie, N.S., ${ }^{2}$ Ghazali, M.I. and ${ }^{1}$ Kormin, F. \\ ${ }^{1}$ Department of Technology and Natural Resources, Faculty of Applied Sciences and Technology, Universiti \\ Tun Hussein Onn Malaysia (UTHM), Kampus Pagoh, KM1, Jalan Panchor 84000 Muar, Johor, Malaysia \\ ${ }^{2}$ Department of Bioprocess and Polymer Engineering Universiti Teknologi Malaysia (UTM), 81310 Johor \\ Bahru, Johor, Malaysia
}

\author{
Article history: \\ Received: 7 November 2019 \\ Received in revised form: 12 \\ February 2020 \\ Accepted: 26 May 2020 \\ Available Online: 4 June \\ 2020
}

\section{Keywords:}

Turmeric,

Curcumin,

Neuroprotection,

Neurodegenerative diseases,

Alzheimer's disease,

Parkinson's disease

DOI:

https://doi.org/10.26656/fr.2017.4(6).363

\begin{abstract}
Turmeric (Curcuma longa) is extensively used as a spice and a coloring agent in Southeast Asia. Turmeric is used as a traditional remedy for cough, diabetic wounds, hepatic disorders, and rheumatism due to its antiseptic, antibacterial, and anti-inflammatory properties. Since the last few decades, extensive work has been done on turmeric and its constituents to explore its pharmacological actions. Curcumin is the main constituent of turmeric and is well demonstrated for its anti-inflammatory, hypoglycaemic, antioxidant, wound-healing, and antimicrobial activities. The functional neurons of the brain and synapses are lost in neurodegenerative disorders for which there is no permanent cure. Oxidative damage and inflammation play a role in age-related neurological disorders. The antioxidants have the ability to prevent different neurological disorders. Recent studies have shown that both turmeric and curcumin possess neuroprotective and cognitiveenhancing properties that help to prevent neurodegenerative diseases like Alzheimer's disease and Parkinson's disease. Different experimental studies have indicated the antioxidant and anti-ageing properties of turmeric and curcumin. Various studies have shown that curcumin acts as a strong barrier against neurological disorders and, hence, it may be a potential drug candidate for the prevention of neurodegenerative diseases. The aim of this review was to present the current pieces of evidence in the literature regarding the neuroprotective effects of turmeric and curcumin.
\end{abstract}

\section{Introduction}

Turmeric is a herbaceous rhizome perennial plant that belongs to the ginger family, Zingiberaceae. Although the origin of turmeric is uncertain, it is thought to be originated from the tropical part of Southeast Asia, most probably India. Now it is also cultivated in Thailand, Indonesia, China, Japan, and Africa. Turmeric is used in food as an active ingredient of curries and mustard (Kim et al., 2014; Yuliani et al., 2019). It is also used as a colouring agent, flavour enhancer and food preservative. It is reported as one of the most investigated medicinal plant species (Jessica Elizabeth et al., 2017). The plant of turmeric is funnel-shaped which is covered with green and white coloured bracts. It has 5 to $5.5 \mathrm{~cm}$ long flowers of yellow colour without any fruit. It is reported that different genotypes of turmeric are rich sources of the essential oils (Akbar et al., 2015; Azmi et al., 2016). Due to a wide spectrum of pharmacological activities, turmeric has received much attention worldwide in recent years. Turmeric possesses antioxidant, anti-inflammatory, anticarcinogenic, antimicrobial and antimutagenic properties (Kuwatada et al., 2017). Turmeric is used as a traditional medicine in the Ayurvedic, Unani and Siddha systems of medicine (Selvi et al., 2015). Its medicinal uses encompass the treatment of different diseases like ulcers, skin diseases, parasitic infections, and to improve the immune system. It is also used for the treatment of cold and flu (Siviero et al., 2015). It has antioxidant (Arya et al., 2015; Lim and Han, 2018), anti-inflammatory, antiproliferative (Amalraj et al., 2017), and anti-ageing (Vaughn et al., 2016) properties. It is also reported to have activity against the protozoans (Llurba-Montesino et al., 2015), venoms (Singh et al., 2017) and tumours (Vemuri et al., 2017). The essential oil, as well as alcoholic and aqueous extracts of turmeric, have shown remarkable pesticidal properties besides acting as a mosquito repellent (Dosoky and Setzer, 2018). 
Coagulation of proteins, inflammation and oxidative damage are characteristic features of many neurodegenerative diseases related to ageing. Curcumin was shown to possess the neuroprotective function as an anti-coagulating agent for protein besides having antiinflammatory and antioxidant properties (Maiti and Dunbar, 2018). The long history of use, low cost, oral safety, pluripotency, and the neuroprotective character make the use of curcumin as a neuroprotective drug of choice in different neurological conditions including neurodegenerative disorders, stroke and ageing (Tamagno et al., 2005). Various studies have shown that turmeric and curcumin ameliorate the symptoms related to dementia (Ahmed and Gilani, 2014; Samy et al., 2016). However, the low absorption, fast metabolic breakdown, and rapid systemic clearance are the factors that limit the bioavailability of curcumin thereby restricting its enormous therapeutic potential (Anand et al., 2007; Yu and Huang, 2012; Prasad et al., 2014; Liu et al., 2016).

Dementia is expressed by an array of clinical symptoms that comprises memory deficit, language problems, and behavioural changes leading to the disturbing activities of daily life. Of all dementia disorders, Alzheimer's disease (AD) is considered as the most prevalent type followed by vascular dementia (VD), mixed dementia (MD), and dementia with Lewy bodies (DLB). Dementia is categorized as a global problem in view of the rapidly ageing population around the globe and the disease puts a significant social and economic burden (Robinson et al., 2015). Accumulation of free radicals and acetylcholine (ACh) deficiency in the brains of Alzheimer's patients is considered as an established factor leading to dementia and cognitive problems. The mechanisms involving a disturbance in a balance between the number of free radicals and the antioxidant (AO) defence system along with cholinergic deficit lead to impaired cholinergic neurotransmission (Ovais et al., 2018; Abu Bakar et al., 2020). According to the epidemiologic studies in Southeast Asian countries, the incidence of $\mathrm{AD}$ is 4.4 times less in comparison to the West because turmeric is commonly used there as a dietary spice ( Mishra and Palanivelu, 2008; Latif et al., 2019). This review attempts to present the neuroprotective role of turmeric in neurodegenerative diseases with a special focus on its therapeutic potential in Alzheimer's and Parkinson's diseases.

\section{Chemical constituents of turmeric}

Turmeric root or rhizome is commonly used in traditional medicine. A large number of different constituents have been identified in turmeric. Polyphenolic curcuminoids constitute the main group of turmeric's bioactive compounds which include curcumin (diferuloylmethane), bisdemethoxycurcumin, demethoxycurcumin, and cyclocurcumin. The yellowpigmented curcuminoids contain $85 \%$ curcumin, $10 \%$ demethoxycurcumin and 5\% bisdemethoxycurcumin. Curcumin is a well-studied compound of turmeric. Turmeric also contains sesquiterpenes (turmerone, zingiberone atlantone, germacrone, turmeronol, and bisabolene), proteins, carbohydrates, resins, and caffeic acid (Jurenka, 2009; Dosoky and Setzer, 2018). Additionally, turmeric has been reported to contain a variety of biochemical compounds involved in a variety of biological functions as summarized in Table 1 .

\section{Curcumin: the most important bioactive compound of turmeric}

Curcumin is a widely studied nutraceutical isolated from the rhizomes of turmeric. It was first discovered about two centuries ago by Vogel and Pelletier, the scientists of Harvard College laboratory (Gupta et al., 2012). The active principle of turmeric is curcumin that is a low molecular weight polyphenol with a bright yellow colour. Curcumin is a highly pleiotropic molecule. This polyphenol has been shown to possess anti-inflammatory, hypoglycaemic, antioxidant, woundhealing, and antimicrobial antiangiogenic, antimutagenic, and antiplatelet aggregation activities. Curcumin is also reported to have nephroprotective activity and shown to work as a therapeutic agent against myocardial infarction, cystic fibrosis, atherosclerosis, neurodegenerative diseases, cancer, rheumatoid inflammation, ocular diseases, osteoporosis, hypertension, chronic kidney diseases, diabetes, chronic inflammation, infection and various skin diseases (Maiti and Dunbar, 2018). Some populations having traditional use of a curcumin-rich diet have shown a low incidence of $\mathrm{AD}$ and their good cognitive ability has been associated with the use of curry, a routine food that contains turmeric which is a source of curcumin (Nakayama et al., 2014). In vivo experiments on the dementia rat model have shown the efficacy of curcumin for the treatment of memory impairment and proved to be a safeguard against oxidative damage (Yaari et al., 2008; Kumar et al., 2009; Agrawal et al., 2010). Despite its demonstrated safety and efficacy, the use of curcumin in chemopreventive or therapeutic settings has been limited by its short biological half-life and low bioavailability. Low serum and tissue levels of curcumin irrespective of the route of administration, rapid metabolism and elimination are some of the major factors curtailing the bioavailability of curcumin. Different studies have also shown that curcumin was poorly bioavailable on oral administration (Ravindranath and Chandrasekhara, 1980; Perkins et al., 2002; Jamwal, 
Table 1. Chemical constituents of turmeric and their effect on the brain

\begin{tabular}{|c|c|}
\hline Turmeric Compounds & Effect on brain \\
\hline $\begin{array}{l}\text { Alpha linolenic acid } \\
\text { (omega-3 fatty acid) }\end{array}$ & $\begin{array}{l}\text { Antioxidant and anti-inflammatory; increases ACh production; increases glucose absorption by cell; anti- } \\
\text { AD; energy production and signaling in brain cells (Kaplan et al., 2017; Ajith, 2018). }\end{array}$ \\
\hline Calebin-A & Antioxidant and anti-inflammatory; neuroprotection (Novaes et al., 2017). \\
\hline Cinnamic acid & Anti-inflammatory (Qabaha et al., 2017); neuroprotection (Prorok et al., 2019). \\
\hline Ferulic acid & Antioxidant; AChE inhibition (Kaur et al., 2018). \\
\hline Vanillic acid & Antioxidant; anti-inflammatory (Kaur et al., 2018). \\
\hline Magnesium & Anti-inflammatory; antioxidant; lowers the rate of dementia and vascular dementia (Novaes et al., 2017). \\
\hline $\begin{array}{c}\text { Thiamine } \\
\text { (vitamin B1) }\end{array}$ & $\begin{array}{l}\text { Deficiency of thiamine causes confusion and memory loss; glucose absorption in brain and nervous } \\
\text { system cells (Kaur et al., 2018; Nedeljković et al., 2018). }\end{array}$ \\
\hline $\begin{array}{l}\text { Riboflavin } \\
\text { (vitamin B2) }\end{array}$ & $\begin{array}{l}\text { Detoxification and excess metal chelation; neuroprotective effects in some neurological conditions (PD, } \\
\text { multiple sclerosis, migraine); antioxidant; myelin formation; mitochondrial function; iron metabolism } \\
\text { (Nedeljković et al., 2018). }\end{array}$ \\
\hline $\begin{array}{c}\text { Niacin } \\
\text { (vitamin B3) }\end{array}$ & $\begin{array}{l}\text { Essential for the production of cell energy; antioxidant; stimulates mitochondria; increases ATP } \\
\text { production; neuronal maturation and neuroprotection (Fricker et al., 2018). }\end{array}$ \\
\hline $\begin{array}{l}\text { Pyridoxine } \\
\text { (vitamin B6) }\end{array}$ & Rate-limiting cofactor in the production of neurotransmitters; neuroprotection (Nedeljković et al., 2018). \\
\hline $\begin{array}{c}\text { Folic Acid } \\
\text { (folate; vitamin B9) }\end{array}$ & $\begin{array}{l}\text { Anti-AD; promotes energy production by mitochondria; memory enhancement and cognitive } \\
\text { improvement; anti-inflammatory (Chen et al., 2016; Cianciulli et al., 2016). }\end{array}$ \\
\hline Vitamin C & $\begin{array}{l}\text { Antioxidant; enhances the immune system; reduces glutamate-mediated excitotoxicity; neuronal } \\
\text { differentiation and maturation; modulation of neurotransmission; increase ATP production (Man Anh et } \\
\text { al., 2019). }\end{array}$ \\
\hline Vitamin E & $\begin{array}{l}\text { Neuroprotective; anti-inflammatory; antioxidant; hypocholesterolemic; cognitive enhancement; reduces } \\
\text { the progression of AD (Lloret et al., 2019). }\end{array}$ \\
\hline Quercetin & $\begin{array}{l}\text { Antioxidant; anti-inflammatory; protection of mitochondria; elimination of extra iron; inhibition of AD } \\
\text { causing TNF- } \alpha \text { and COX-2 (Khan et al., 2018). }\end{array}$ \\
\hline Resveratrol & $\begin{array}{l}\text { Antioxidant; protection against neurodegenerative diseases and assembly of A } \beta \text { protein by activating } \\
\text { SIRT1 longevity gene (Gomes et al., 2018); prevention of brain cell death in hippocampus (Kodali et al., } \\
\text { 2015); inhibition of inflammatory enzymes (de Sá Coutinho et al., 2018); protection of brain cells from } \\
\text { injury by stimulating vitagenes; clearance of } \alpha \text {-synuclein (Guo et al., 2016); protects from metabolic stress } \\
\text { (Palomera-Avalos et al., 2017). }\end{array}$ \\
\hline Turmerones & Blocks $A \beta$ production and aggregation (Maiti and Dunbar, 2018). \\
\hline Xanthorrhizol & Neuroprotection; antioxidant; anti-inflammatory; anti-A $\beta$ (Lim and Han, 2018). \\
\hline Zingib & ducts (AGEs) in \\
\hline
\end{tabular}

2018).

\section{Neurodegenerative diseases and neuroprotection}

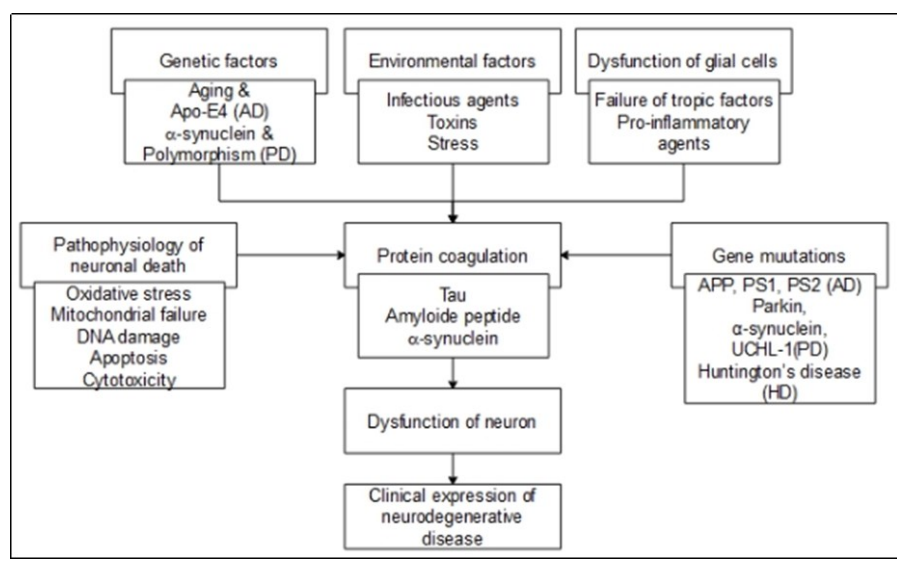

Figure 1. The causes of neurodegeneration including neuronal death gene mutation, genetic factors, environmental factors and dysfunctioning of cells involving protein coagulation and then neuronal death with clinical expression of neurodegenerative diseases.

The etiology of neurodegeneration involves various environmental and genetic factors, genetic mutations, pathophysiological processes of neuronal death, and dysfunction of glial cells (Figure 1). Degeneration of the central nervous system leads to cell death, failure of axon regeneration, demyelination, and in general the structural and functional neuronal deficits. All these conditions partly or completely, single or combined, genetic or attained, are demonstrated in neurological disorders, collectively known as neurodegenerative disorders. These disorders are harmful to the normal functioning of the brain and cause progressive deterioration as they are one of the leading causes of disability and mortality. There are various neurodegenerative disorders but special attention has been given to $\mathrm{AD}$, Parkinson's disease (PD), Amyotrophic lateral sclerosis (ALS), and Huntington disease (HD) (Hussain et al., 2018). Although there are hundreds of neurodegenerative diseases, their classification is quite challenging in view of their overlapping clinical and pathological symptoms. Neurodegenerative diseases may be grouped into a disease of ganglion, cortex, brainstem, cerebellum or spinal cord. Among neurodegenerative diseases, AD is the sixth leading cause of death in the world (McMackin et al., 2019; Weis et al., 2019). Studies have shown that 
the increased level of age-dependent neurodegeneration is associated with increased oxidative damage to protein, lipids, and DNA with a decrease in antioxidant levels (Lee et al., 2012; Höhn and Grune, 2013). In neurodegenerative diseases, the modification of oxidative proteins occurs at a low level that accumulates in a variety of cells and tissues (Zhang, 2013).

The term neuroprotection means the ability to defend the central nervous system from an acute neural injury such as stroke or trauma, and chronic neurodegenerative disorders like $\mathrm{AD}$ and $\mathrm{PD}$. In this respect, herbal medicines may play a valuable role in the prevention of neurodegenerative diseases with a healthy lifestyle including good physical activity and dietary habits. The medicinal use of plant organs like roots, stem, leaves, flowers, fruits, and seeds in herbal medicine is a complementary and alternative method of treatment. The plant products contain a complex mixture of phytochemicals compounds (Nour et al., 2014; Fazel Nabavi et al., 2016; Spagnuolo et al., 2016).

\section{Potential therapeutic targets neurodegenerative disorders}

in

The neurodegenerative disorders constitute the most common forms of dementia but the identification of suitable therapeutic targets is restricted due to a variety of aetiologies involved. Except for the inherited AD and $\mathrm{VD}$, the underlying aetiologies are still unidentified for most dementia disorders. However, multiple pathologies leading to potential therapeutic targets include amyloidbeta $(\mathrm{A} \beta)$ and abnormal tau proteins for $\mathrm{AD}$, angiogenic and ischemic lesions for $\mathrm{VD}$, and $\alpha$-synucleinopathy for LBD, primarily cholinergic neurotransmitter defects, inflammatory pathways, oxidative stress, apoptosis, and diminished neuroplasticity (Kumar and Singh, 2015; Zhou et al., 2016). Other therapeutic targets include the cholinesterase inhibitors (ChEIs) which act as anti-AChE thereby enhancing the cholinergic neurotransmission by increasing the ACh level at the synaptic junction; secretase inhibitors including $\beta$-secretase and $\gamma$-secretase which prevent the deposition of the amyloid plaques in brain by restricting the synthesis of $A \beta_{1-42}$ fragment from amyloid precursor protein (APP); anti-inflammatory drugs including cyclooxygenase (COX) inhibitors which act by decreasing the neurotoxic COX level thereby reducing the inflammation of brain tissue, and antioxidants including the drugs which combat the free radicals which are considered as one of the main factors that oxidatively injure the brain tissue (Natarajan et al., 2013).

\section{Turmeric and neurological disorders}

Neurological disorders are defined as the disorders of the peripheral and central nervous system including the brain, spinal cord, nerves, autonomic nervous system, and neuromuscular junction, muscles leading to $\mathrm{AD}, \mathrm{PD}$, epilepsy, migraine, and brain tumours (Khan et al., 2018). The use of turmeric in medicine is due to its chemical composition. Turmeric contains almost 235 compounds among which curcuminoids are the most bioactive compounds containing curcumin. A study on turmeric consumption and cognitive function in Asian people showed that the elderly Asians who use curry (once a month or more) containing turmeric had a superior cognitive function as compared to those who rarely consume curry (less than one in six months). They have higher Mini-Mental State Examination (MMSE), which proves their superior cognitive function ( $\mathrm{Ng}$ et al., 2006; Suryanarayana et al., 2007; Yao and Xue, 2014). Turmeric was found effective for behavioural and psychological symptoms of dementia (BPSD) treatment including hallucination, apathy, delusions, agitation, anxiety, and depression. In a clinical study on turmeric administration, a decrease in the acuity of symptoms was observed (Huang et al., 2012).

There are many molecular targets like transcription factors, kinases, inflammatory cytokinases, antioxidants and growth factors which are modulated and communicated by curcumin. All these actions of curcumin are due to its neuroprotective activity. Various pathways in different types of cells of the nervous system like neurons, astrocytes, and microglia (Lavoie et al., 2009; Maiti and Dunbar, 2018) have explained this supportive effect of curcumin. The curcumin was observed to possess a neuroprotective function in the primary cell culture of different areas of the nervous system, for instance, in cortical (Wang et al., 2012), mesencephalic (Ortiz-Ortiz et al., 2010), spinal cord (Jiang et al., 2011), and hippocampal regions (Ye and Zhang, 2012), due to its antioxidant, anti-inflammatory and anti-protein coagulating properties. Curcumin was reported to reduce the expression of interleukin-1 alpha (IL-1 $\alpha$ ), interleukin-6 (IL-6), and tumour necrosis factoralpha (TNF- $\alpha$ ) in the neurodegenerative disorder due to which the neuro-inflammation decreased (Darvesh et al., 2012; Hatami et al., 2019). The brain cells have high oxygen demand due to which they are more sensitive to oxidative damage. The oxidation of unsaturated fatty acid 4- hydroxy-2,3-nonenal, acrolein, malondialdehyde (MDA) and other compounds as an end product have a negative impact on human health (Ayala et al., 2014). The glutathione peroxidase (GPx), superoxide dismutase (SOD), and catalase (CAT) are endogenous antioxidant enzymes which protect the cells against oxidative damage due to a high content of unsaturated fatty acids in the brain (Kim et al., 2015). The antioxidant defense system of the brain is weaker as compared to other body 
parts. So the oxidative stress rapidly leads to the hippocampus degeneration, which is the major memory processing region. Such degeneration may lead to the pathogenesis of neurodegenerative diseases including dementia (Liu et al., 2017). The organometal trimethyltin (TMT) has a harmful effect on the brain by enhancing the formation of reactive oxygen species (ROS) in the hippocampus region. TMT also enhances the expression of presenilin, APP, and c-fos (a transcription factor) in the limbic system, which are linked to the pathophysiology of $\mathrm{AD}$. The ethanolic turmeric extract reduces the TMT-induced oxidative stress by decreasing the level of plasma and brain MDA and increases the levels of SOD, glutathione (GHS), CAT, and GPx enzymes in the brain (Yuliani et al., 2019). Curcumin was shown to improve the survival of cortical neurons deprived of oxygen and glucose and concomitant cell injury in an in vitro study. Moreover, the results of this study also suggested a decrease in the volume of infarct and oxidative stress following the focal cerebral ischemia in rats (Li et al., 2017). Figure 2 summarizes the neuroprotective effects of curcumin.

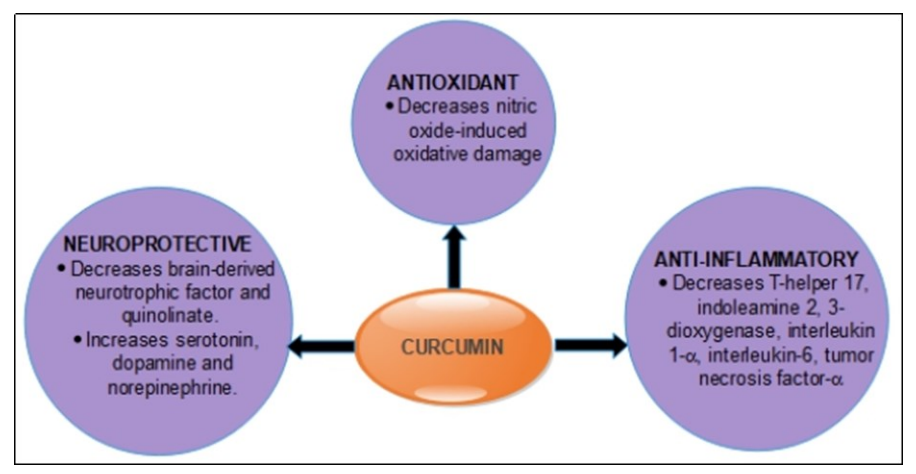

Figure 2. Neuroprotective effects of curcumin

\section{Role as antioxidant}

An antioxidant is a molecule, which, in a concentration lower than its oxidizable substrate, has the ability to substantially retard or delay the substrate oxidation (Galano, 2015). Antioxidants inhibit the catalysis of ROS generation by removing and scavenging the ROS and ROS precursors. Various studies have indicated that brain tissue in dementia patients are exposed to oxidative stress (Liu et al., 2017; Khan et al., 2018). High oxygen demand, terminal neuronal differentiation, and weak antioxidant mechanisms make the central nervous system (CNS) more prone to oxidative stress, which in turn triggers various neurodegenerative disorders (Kim et al., 2015). Several studies have indicated the efficacy of various antioxidants to prevent cognitive decline (Wong et al., 2018), as the treatment options for mild cognitive impairment (MCI) and AD (Mecocci et al., 2004; Cristina Polidori and Nelles, 2014). Age-associated increase in oxidative stress is considered as one of the significant risk factors for cognitive decline (Konar et al., 2016) and is widely thought to be a significant feature in the complexity of $\mathrm{AD}$ pathogenicity (Shen et al., 2018). Consequently, there is a growing interest to explore the role of antioxidants in preventing or retarding the initiation of cognitive decline. Generally, an imbalance between the ROS production and the physiological antioxidant defence system is termed as oxidative stress resulting in a shift in the redox state linked to an increased production of ROS which ultimately leads to increased oxidation of lipids, DNA, protein, neurons, and apo E4, all of which are the risk factors for cognitive ageing (Lacour et al., 2017; Legdeur et al., 2018).

\subsection{Animal studies in mice}

Naik et al. (2011) studied the antioxidant activity of curcumin at a dosage of $200 \mathrm{mg} / \mathrm{kg}$ in Wistar strain rats and reported a correlation of its antioxidant activity with hepatoprotective, anti-inflammatory and cardioprotective effects. Banji et al. (2014) have described that curcumin improved cognition by suppressing the mitochondrial dysfunction and apoptosis induced by D-galactose in rat brains thereby increasing the antioxidant content in neuronal mitochondria. Ciftci et al. (2015) have reported the curcumin-mediated prevention of formaldehydeinduced neurotoxicity in rats. Cui et al. (2016) have shown that curcumin ameliorated the dopamine-induced neuronal oxidative damage by decreasing the ROS production and increasing the levels of GSH in rat brain cells. Saha et al. (2016) reported that curcumin prevented pentylenetetrazole (PTZ)-induce neurotoxicity via decreasing the ROS and nitric oxide (NO) levels and increasing the levels of GSH and antioxidant enzymes. Samy et al. (2016) have shown that curcumin treatment led to the prevention of AD in streptozotocin (STZ)induced Alzheimer's dementia in rats by modulating apoptosis and oxidative stress. Sankar et al. (2016) reported that curcumin prevented the arsenic-induced neurotoxicity and oxidative damage by decreasing lipid peroxygenase (LPO) levels and increasing the levels of GSH and antioxidant enzymes. Waseem and Parvez (2016) reported the preventive effect of curcumin in response to the neurotoxicity and mitochondrial dysfunction induced by oxaliplatin. Sharma et al. (2014) have shown that curcumin attenuated the fluorideinduced neurotoxicity and prevented the neurodegeneration by decreasing the level of LPO in the hippocampal region. Nazari et al. (2014) reported a neuroprotective effect of highly bioavailable curcumin on sodium nitroprusside-induced oxidative stress model by decreasing oxidative stress.

\section{Turmeric and Alzheimer's disease}


Alzheimer's disease is a widespread disease especially in industrialized western countries. The disease rate is higher in the US and European countries than in Asia (Zhang et al., 2018). In AD, two major lesions are formed: senile plaques and neurofibrillary tangles (NFT). In senile plaques, dystrophic neurites and activated glial cells are likely to be more central protein deposits of amyloid fibrils that are made up of $A \beta$ peptide (Luchena et al., 2018; Ziegler-Waldkirch and Meyer-Luehmann, 2018). Turmeric contains different compounds including curcumin, tetrahydrocurcumin, bisdemethoxycurcumin, and demethoxycurcumin, which act as anti-amyloidogenic by preventing the $A \beta$ protein formation, the pathological root cause of $\mathrm{AD}$ (Zhang et al., 2010; Randino et al., 2016). It is stated that a low dose of turmeric (160 ppm) can reduce pro-inflammatory cytokine levels which are linked to the neuroinflammatory cascades involved in the neuritic plaque pathogenicity (Lim et al., 2001). In AD, the faulty phagocytosis occurs due to which $A \beta$ plaques cannot be cleared effectively. Curcumin triggers the phagocytosis due to which the $A \beta$ plaques are cleared in vitro and enhance the induction of heat shock protein (HSP) in reaction to the addition of soluble $A \beta$ aggregates to neuronal cell cultures. It also reduces the strength of $A \beta$ amassing and prevents the formation of A $\beta$ fibrils in these cells (Cline et al., 2018; Maiti and Dunbar, 2018). It was suggested that the regulation of nuclear factor kappa-light-chain-enhancer of activated B cells $\left(\mathrm{NF}-{ }_{\mathrm{K}} \mathrm{B}\right)$ activity-associated transcription factors, that is, cytokines and enzymes, was responsible for the therapeutic potential of curcumin in $\mathrm{AD}$ (Lee et al., 2013). Epidemiological studies of turmeric show its nonsteroidal anti-inflammatory property, which is linked with reducing the risk of AD (He et al., 2015). Thus, it may be concluded that turmeric increases the neurocognitive function in Alzheimer's patients.

The major active component of turmeric, the curcumin has some interesting properties. It regulates the level of dopamine, norepinephrine, and serotonin in the brain and inhibits the enzyme monoamine oxidase (MAO) A and B, which decompose serotonin and dopamine (Kulkarni et al., 2008; Wang et al., 2014). The role of serotonin is in the neuro-vegetative function of the body such as sleep, appetite, learning and memory, behaviour, mood, muscle contraction, cardiovascular function and regulation of endocrine, while dopamine is involved in emotion, pleasure and regulating locomotion. A neurotransmitter, norepinephrine, is involved inattentiveness, sleeping, dreaming, emotion and learning. Turmeric modifies the dysfunction of these neurotransmitters and significantly reduces behavioural symptoms of AD (Zhao et al., 1989; Cole et al., 2004). It is suggested by a clinical study that curcumin decreases the oxidative damage and removes the stimulus for $\mathrm{A} \beta$ formation. It also reduces the inflammation in microglial cells of the brain by reducing the cytokines level which is pro-inflammatory signalling molecules and by preventing the formation of $A \beta$, thereby decreasing the $\mathrm{A} \beta$ plaques. It generates an enzyme which reduces the risk of $A \beta$ production and lowers the oxidation of those fats and proteins which are dangerous. It triggers the macrophage cells of the brain to clear the $A \beta$ plaques which are already present. It inhibits $A \beta$ aggregation and reverses the neurodegeneration due to $A \beta$ production and also inhibits the $A \beta$ mediated neurotoxicity. It also blocks the cholesterol formation that is also a factor involved in the formation of $\mathrm{A} \beta$ (Tang and Taghibiglou, 2017).

In an in-vitro study, it was shown that curcumin has the ability to reduce the number of plaques in the brain by impending $A \beta$ plaques formation (Ahmed and Gilani, 2014). The higher concentration of curcumin at the molecular level binds to $A \beta$ to block self-assembly. As curcumin is lipophilic in nature, it easily crosses the blood-brain barrier (BBB) and then binds to the $A \beta$ plaques. Curcumin has metal chelating property as it has the ability to bind with the metal ions and improve the $\mathrm{A} \beta$ degradation and decreases the oxidative stress (Maiti and Dunbar, 2018; Reddy et al., 2018). It binds with iron, copper with high affinity rather than zinc thereby acting as a protector against $\mathrm{AD}$, and may protect against iron-mediated damage (Tang and Taghibiglou, 2017). A decreased serum $A \beta$ level along with a reduction in $A \beta$ burden in the brain, that was more prominent in the regions of neocortex and hippocampus, resulted after the administration of curcumin to an AD mouse model (Farooqui et al., 2018; Wang et al., 2012). These studies highlight the promising role of turmeric and curcumin in the inhibition of $A \beta$ plaques formation and, hence, their ability to improve the neurodegenerative disease condition.

\subsection{Animal studies in mice}

Dohare et al. (2008) studied the neuroprotective activity of Curcuma oil $(250 \mathrm{mg} / \mathrm{kg})$ in Sprague-Dawley male rats and reported that Curcuma oil promoted the suppression of increasing intracellular concentration of $\mathrm{Ca}^{2+}$ that is considered as an important player in different signalling pathways. They also reported that the curcuma oil caused a decrease in ROS generation leading to the prevention of brain neutrophils and NO metabolites infiltration following ischemia in the brain. The neuroprotective activity of curcumin in Sprague-Dawley male rats at a dosage of $300 \mathrm{mg} / \mathrm{kg}$ was also reported by Dohare et al. (2008) also reported that curcumin-induced selective inhibition of neuronal cytotoxicity. Also, they 
stated that curcumin treatment significantly attenuated the increased volumes of brain infarct and edema following ischemia in rats. Zhang et al. (2008) investigated the neuroprotective activity of curcuminoids (1-10 $\mu \mathrm{mol})$ in newborn Sprague-Dawley rats and revealed that curcuminoids significantly suppressed the NO production by LPS-activated microglia in rat brain. Jayanarayanan et al. (2013) described the neuroprotective activity of curcumin in STZ-induced Wistar male rats at a dosage of $60 \mathrm{mg} / \mathrm{kg}$ and reported the beneficial effect of curcumin supplementation to STZ -induced diabetic rats thereby reducing the alterations in glutamatergic receptors, imbalanced glutamate metabolism, and oxidative stress. Eckert et al. (2013) reported the effect of curcumin on mitochondrial dysfunction in brain of male Senescence Accelerated Mouse Prone-Strain 8 (SAMP8) and Senescence Accelerated Mouse Resistant-Strain 1 (SAMR1) at a dosage of $500 \mathrm{mg} / \mathrm{kg}$ and observed a significant decrease in mitochondrial dysfunction and energy production in the brain cells of SAMP8 mice. Chen et al. (2014) studied the neuroprotective activity of curcumin at a dosage of $500 \mathrm{nmol} / \mathrm{L}$ in Sprague-Dawley female rats (pregnant for 14.5 days) and reported that the neuroprotective effect of curcumin was through upregulation of wnt3a and $\beta$-catenin expression in the control experimental group receiving curcumin at a dose of $500 \mathrm{nmol} / \mathrm{L}$. Gazal et al. (2014) described that pretreatment of a ketamine-induced model of mania in female adult Wistar rats with curcumin led to the prevention of ketamine-induced behavioral and prooxidant effects. Ahmed and Gilani (2009) studied the anti-AD effects of curcuminoids and its individual components at a dosage range of $3-10 \mathrm{mg} / \mathrm{kg}$ in SpragueDawley male rats and reported their memory enhancing capacity in addition to the dose-dependent inhibitory effect in frontal cortex and hippocampus as well as ex vivo acetylcholinesterase assay. Ahmed et al. (2010) described that the anti-AD effect of curcuminoids and its individual components at a dosage range of $3-10 \mathrm{mg} / \mathrm{kg}$ in $A \beta$ peptide-infused Sprague-Dawley male rats was due to the curcuminoids-mediated increased expression of synaptophysin. These data suggest the importance of diet supplemented with curcumin as a preventive measure and treatment option for $\mathrm{AD}$ that may decrease $\mathrm{A} \beta$ and plaque burden in addition to lowering the oxidative stress in the brain.

\subsection{Clinical trials using curcumin for AD therapy}

Some investigations regarding the preclinical trials to test the efficacy of curcumin in humans along with the pharmacokinetics and safety have been reported in the literature. The oral administration of curcumin in twentyfive patients of neurodegenerative diseases at a dose range of 500-8000 $\mathrm{mg}(1.36-2.17 \mathrm{mmol} /$ day $)$ for a period of three months was reported to have no noticeable toxicity (Hsieh, 2001). In another preclinical study, the oral administration of curcumin in 24 healthy volunteers at a single dose ranging from 500 to $12000 \mathrm{mg}$ (1.36$32.6 \mathrm{mmol}$ ) resulted in dose-independent minimal toxicity in $30 \%$ volunteers. This study concluded that curcumin could be safely administered to patients at a single dose of 12 grams, and up to 8 grams per day for a period of three months (Lao et al., 2006). Baum et al. (2008) performed a double-blind, randomized, placebocontrolled study on $34 \mathrm{AD}$ patients. The participants were randomly assigned for oral administration of curcumin at two different doses from 1 or $4 \mathrm{~g}$ or placebo at a dose of $4 \mathrm{~g}$. The study revealed that there was no improvement in the Mini-Mental State Examination (MMSE) score that assesses the mental status after curcumin treatment. Moreover, there was no effect of curcumin treatment on the level of serum $A \beta_{40}$. However, curcumin treatment was found in association with an increase in vitamin $\mathrm{E}$ level, without any adverse side effects. It was concluded that the increase in the level of vitamin $\mathrm{E}$ might be in response to the antioxidant activity of curcuminoids leading to a decrease in the need for antioxidant vitamin E. Lopresti et al. (2014) conducted a randomized, double-blind, and placebocontrolled study on human subjects aged 18 to 65 and reported a more significant effect of curcumin than placebo on the improvement of several mood-related symptoms. It may be inferred from these studies that there is a need to open a clinical trial of curcumin against $\mathrm{AD}$ based on a large number of patients.

\section{Therapeutic role in Parkinson's disease}

Parkinson's disease is another prevalent age-related neurodegenerative condition. It is associated with selective exposure to the neuromelanin containing dopaminergic neurons pars compacta region of the substantia nigra of the midbrain and their terminals in the striatum. In PD, the death of dopaminergic neurons occurs in this region and the symptoms of PD can't be recognized until $60-80 \%$ of neurons are lost. Among the age-related neurodegenerative disorders, PD is strongly associated with an increased rate of oxidative damage. It is also linked with the auto-oxidative breakdown of dopamine and metabolism of semiquinone to superoxides (Blesa et al., 2015; Magalingam et al., 2015; Maiti et al., 2017). Turmeric has antioxidant and antiinflammatory properties which help in PD as the studies show that turmeric is helpful in preventing the chronic inflammation that causes the neurodegeneration and brain cell malfunctioning. Many conditions are included in association with metabolic disorders like diabetes, high cholesterol level, insulin resistance, hypertension, 
fatty liver, and psychological stress (Hewlings and Kalman, 2017; Abdel-Salam, 2019). Turmeric contains resveratrol, quercetin and vitamin $\mathrm{C}$ which can assist to conduct heme oxygenase-1 (HO-1) production. Curcumin enhances the response against heat shock and also stimulates the vitagenes HO-1 and Hsp-70. Due to this effect of curcumin, the body enhances the production of its own antioxidants which help to defend the brain against free radical damage. According to some reports, excessive HO-1 can deposit iron in those cells which are damaged in PD, however, animal studies show that only the protective amounts are induced by curcumin. In vitro studies have shown that curcumin enhances the body's effective natural antioxidant enzyme, superoxide dismutase (Mazzio et al., 2011; Kim et al., 2016; Yang et al., 2017; Abdel-Salam, 2019).

A low dose of curcumin was reported to inhibit the toxicity of dopamine in vivo (Luo et al., 1999; Maiti et al., 2017). The oxidative damage to selective dopaminergic neuron and consequent $\mathrm{PD}$ can be produced by 1-methyl-4-phenyl-1, 2, 3, 6tetrahydropyridine (MPTP) toxins in human and animal models showing the defect in complex I of mitochondrial electron transport chain as well as an increase in the production of free radicals in brain and peripherals region are also identified (Mehlhorn and Cole, 1985; Dias et al., 2013; Subramaniam and Chesselet, 2013). The toxicity of MPTP is mediated by MPP ${ }^{+}$, and toxicity of $\mathrm{MPP}^{+}$to the neuronal cell line PC12 is inhibited by curcumin and cyclocurcumin (Chakraborty et al., 2017). The aggregation of fibre-forming protein, that is, $\alpha$ synuclein is a major part of LB lesions that is the characteristics of $\mathrm{PD}$ as well as $\mathrm{AD}$, and other neurological disorders (Melki, 2015).

The clinical application of curcumin is strongly supported in PD through several studies. According to Song et al. (2016), curcumin is a promising applicant for $\mathrm{PD}$ as it improves the neuro functions of substantia nigra neurons by regulating intracellular expressions of SOD, NGF, GSH, and Hsp70. Gadad et al. (2012) showed that curcumin inhibited additional fibrillization of $\alpha$ synuclein by binding with the $\alpha$-synuclein oligomer. Phom et al. (2014) reported that curcumin refreshes the consumed dopamine level in early PD while its effect is limited as a therapeutic agent in the later stages. Curcumin was shown to reverse the decrease in the levels of dopamine and its metabolite 3, 4dihydroxyphenylacetic levels induced by hydroxydopamine (6-OHDA) in the striatum. Furthermore, curcumin was able to restore the concentration of tyrosine hydroxylase-positive neurons along with a decrease in the concentration of ironpositive cells in comparison with the control group treated with 6-OHDA. Curcumin was reported to attenuate the neurotoxin-triggered loss of striatal dopamine axons at the same dose for seven days following post 6-OHDA injection. The neuroprotective activity of curcumin has been attributed to the inhibition of astroglial and microglial reaction, as indicated by a decreased levels of glial fibrillary acidic protein and immunoreactivity of ionized calcium-binding adapter molecule 1, in addition to maintaining the level of superoxide dismutase 1 (Kujawska and Jodynis-Liebert, 2018).

\section{Conclusion}

Turmeric is extensively used as a spice and a colouring agent in Southeast Asia. It is also used in traditional systems of medicine since ancient times. Turmeric and its compounds have different medicinal applications. Curcumin that is the main constituent of turmeric is a pleiotropic molecule having antioxidant and anti-inflammatory properties. Due to these properties, turmeric and curcumin are reported as neuroprotective agents in the neurodegenerative disease especially $\mathrm{AD}$ and PD. As currently available drug therapies for neurodegenerative diseases including $\mathrm{AD}$ and $\mathrm{PD}$ have proven little efficacy with many side effects, the nutraceutical approach using a safe and economical compound such as curcumin may open a new avenue for the management and treatment of these diseases. However, the limited bioavailability of curcumin is one of the major barriers to such a nutraceutical approach for the treatment of neurodegenerative diseases involves. This issue can be solved by different strategies involving chemical modification or co-administration of curcumin with those compounds that may facilitate its absorption. Although there are some promising reports regarding the efficacy of curcumin in neurodegenerative diseases, the clinical trials have not provided conclusive evidence regarding the treatment of such diseases by administering curcumin. In order to establish the efficacy of curcumin in neurodegenerative disorders like $\mathrm{AD}$ and $\mathrm{PD}$, it is imperative to conduct well-designed large-scale clinical trials and preventive interventions.

\section{Conflicts of interest}

The authors declare that there is no conflict of interest regarding the publication of this review paper.

\section{Acknowledgement}

This research was financially supported by the Ministry of Higher Education (MOHE), under Fundamental Research Grant Scheme (FRGS) Vot no. FRGS/1/2018/WAB13/UTHM/02/2 and Research 
Management Centre (RMC), Universiti Tun Hussein Onn Malaysia through Geran Penyelidikan Pascasiswazah (GPPS) Vot. No. 489 in addition to Research Fund Vot no. E15501.

\section{References}

Abdel-Salam, O.M. (2019). Use of Herbal Products/ Alternative Medicines in Neurodegenerative Diseases (Alzheimer's Disease and Parkinson's Disease). In Singh, S. and Joshi, N. (Eds). Pathology, Prevention and Therapeutics of Neurodegenerative Disease, p. 279-301. Singapore: Springer. https://doi.org/10.1007/978-981-13-09441_24

Abu Bakar, F., Abu Bakar, M.F., Hassan, S., Sanusi, S., Kormin, F., Sabran, S.F. and Fuzi, S. (2020). Comparison of phytochemicals, antioxidant and anticholinesterase activity of unripe and ripe fruit of Sonneratia caseolaris. Food Research, 4(2), 507514. https://doi.org/10.26656/fr.2017.4(2).277

Agrawal, R., Mishra, B., Tyagi, E., Nath, C. and Shukla, R. (2010). Effect of curcumin on brain insulin receptors and memory functions in STZ (ICV) induced dementia model of rat. Pharmacological Research, 61(3), 247-252. https://doi.org/10.1016/ j.phrs.2009.12.008

Ahmed, T., Enam, S. and Gilani, A. (2010). Curcuminoids enhance memory in an amyloidinfused rat model of Alzheimer's disease. Neuroscience, 169(3), 1296-1306. https:// doi.org/10.1016/j.neuroscience.2010.05.078

Ahmed, T. and Gilani, A.-H. (2009). Inhibitory effect of curcuminoids on acetylcholinesterase activity and attenuation of scopolamine-induced amnesia may explain medicinal use of turmeric in Alzheimer's disease. Pharmacology Biochemistry and Behavior, 91(4), 554-559. https://doi.org/10.1016/ j.pbb.2008.09.010

Ahmed, T. and Gilani, A.H. (2014). Therapeutic potential of turmeric in Alzheimer's disease: curcumin or curcuminoids? Phytotherapy Research, 28(4), 517-525. https://doi.org/10.1002/ptr.5030

Ajith, T.A. (2018). A recent update on the effects of omega-3 fatty acids in Alzheimer's disease. Current Clinical Pharmacology, 13(4), 252-260. https:// doi.org/10.2174/1574884713666180807145648

Akbar, A., Kuanar, A., Sandeep, I., Kar, B., Singh, S., Mohanty, S., Patnaik, J. and Nayak, S. (2015). GCMS analysis of essential oil of some high drug yielding genotypes of turmeric (Curcuma longa L.). International Journal of Pharmacy and Pharmaceutical Sciences, 7(9), 35-40.
Amalraj, A., Pius, A., Gopi, S. and Gopi, S. (2017). Biological activities of curcuminoids, other biomolecules from turmeric and their derivatives-A review. Journal of Traditional and Complementary Medicine, 7(2), 205-233. https://doi.org/10.1016/ j.jtcme.2016.05.005

Anand, P., Kunnumakkara, A.B., Newman, R.A. and Aggarwal, B.B. (2007). Bioavailability of curcumin: problems and promises. Molecular Pharmaceutics, 4 (6), 807-818. https://doi.org/10.1021/mp700113r

Arya, N., Prakash, O., Verma, A. and Pant, A. (2015). Variation in antioxidant potential of Curcuma longa L. collected from different ecological niches of Western Himalayan region. International Journal of Pharmacy Pharmaceutical Sciences, 7(7), 85-90.

Azmi, N.S., Bhat, R. and Yeoh, T. (2016). Quality evaluation of novel cookies prepared by supplementing with fresh turmeric flower (Curcuma longa L.) extracts as a value added functional ingredient. International Food Research Journal, 23 (4), 1514-1522.

Banji, O.J., Banji, D. and Ch, K. (2014). Curcumin and hesperidin improve cognition by suppressing mitochondrial dysfunction and apoptosis induced by D-galactose in rat brain. Food and Chemical Toxicology, 74, 51-59. https://doi.org/10.1016/ j.fct.2014.08.020

Baum, L., Lam, C.W.K., Cheung, S.K.-K., Kwok, T., Lui, V., Tsoh, J., Lam, L., Leung, V., Hui, E. and $\mathrm{Ng}$, C. (2008). Six-month randomized, placebocontrolled, double-blind, pilot clinical trial of curcumin in patients with Alzheimer disease. Journal of Clinical Psychopharmacology, 28(1), 110 -113. https://doi.org/10.1097/jcp.0b013e318160862c

Blesa, J., Trigo-Damas, I., Quiroga-Varela, A. and Jackson-Lewis, V.R. (2015). Oxidative stress and Parkinson's disease. Frontiers in Neuroanatomy, 9, 91. https://doi.org/10.3389/fnana.2015.00091

Chakraborty, S., Karmenyan, A., Tsai, J.-W. and Chiou, A. (2017). Inhibitory effects of curcumin and cyclocurcumin in 1-methyl-4-phenylpyridinium $(\mathrm{MPP}+)$ induced neurotoxicity in differentiated PC12 cells. Scientific Reports, 7(1), 16977. https:// doi.org/10.1038/s41598-017-17268-3

Chen, F., Wang, H., Xiang, X., Yuan, J., Chu, W., Xue, X., Zhu, H., Ge, H., Zou, M. and Feng, H. (2014). Curcumin increased the differentiation rate of neurons in neural stem cells via wnt signaling in vitro study. Journal of Surgical Research, 192(2), 298-304. https://doi.org/10.1016/j.jss.2014.06.026

Chen, H., Liu, S., Ji, L., Wu, T., Ji, Y., Zhou, Y., Zheng, M., Zhang, M., Xu, W. and Huang, G. (2016). Folic 
acid supplementation mitigates Alzheimer's disease by reducing inflammation: a randomized controlled trial. Mediators of Inflammation, 2016, 5912146. https://doi.org/10.1155/2016/5912146

Cianciulli, A., Salvatore, R., Porro, C., Trotta, T. and Panaro, M.A. (2016). Folic acid is able to polarize the inflammatory response in LPS activated microglia by regulating multiple signaling pathways. Mediators of Inflammation, 2016, 5240127. https:// doi.org/10.1155/2016/5240127

Ciftci, G., Aksoy, A., Cenesiz, S., Sogut, M.U., Yarim, G. F., Nisbet, C., Guvenc, D. and Ertekin, A. (2015). Therapeutic role of curcumin in oxidative DNA damage caused by formaldehyde. Microscopy Research Technique, 78(5), 391-395. https:// doi.org/10.1002/jemt.22485

Cline, E.N., Bicca, M.A., Viola, K.L. and Klein, W.L. (2018). The amyloid- $\beta$ oligomer hypothesis: Beginning of the third decade. Journal of Alzheimer's Disease, 64(S1), S567-S610. https:// doi.org/10.3233/JAD-179941

Cole, G.M., Morihara, T., Lim, G.P., Yang, F., Begum, A. and Frautschy, S.A. (2004). NSAID and antioxidant prevention of Alzheimer's disease: lessons from in vitro and animal models. Annals of the New York Academy of Sciences, 1035(1), 68-84. https://doi.org/10.1196/annals.1332.005

Cristina Polidori, M. and Nelles, G. (2014). Antioxidant clinical trials in mild cognitive impairment and Alzheimer's disease-challenges and perspectives. Current Pharmaceutical Design, 20(18), 3083-3092. https://doi.org/10.2174/13816128113196660706

Cui, Q., Li, X. and Zhu, H. (2016). Curcumin ameliorates dopaminergic neuronal oxidative damage via activation of the Akt/Nrf2 pathway. Molecular Medicine Reports, 13(2), 1381-1388. https://doi.org/10.3892/mmr.2015.4657

Darvesh, A.S., Carroll, R.T., Bishayee, A., Novotny, N.A., Geldenhuys, W.J. and Van der Schyf, C.J. (2012). Curcumin and neurodegenerative diseases: a perspective. Expert Opinion on Investigational Drugs, 21(8), 1123-1140. https:// doi.org/10.1517/13543784.2012.693479

de Sá Coutinho, D., Pacheco, M.T., Frozza, R.L. and Bernardi, A. (2018). Anti-inflammatory effects of resveratrol: Mechanistic insights. International Journal of Molecular Sciences, 19(6), 1812. https:// doi.org/10.3390/ijms 19061812

Dias, V., Junn, E. and Mouradian, M.M. (2013). The role of oxidative stress in Parkinson's disease. Journal of Parkinson's Disease, 3(4), 461-491. https:// doi.org/10.3233/JPD-130230
Dohare, P., Varma, S. and Ray, M. (2008). Curcuma oil modulates the nitric oxide system response to cerebral ischemia/reperfusion injury. Nitric Oxide, 19(1), 1-11. https://doi.org/10.1016/ j.niox.2008.04.020

Dosoky, N.S. and Setzer, W.N. (2018). Chemical composition and biological activities of essential oils of Curcuma species. Nutrients, 10(9), 1196. https:// doi.org/10.3390/nu10091196

Eckert, G.P., Schiborr, C., Hagl, S., Abdel-Kader, R., Müller, W.E., Rimbach, G. and Frank, J. (2013). Curcumin prevents mitochondrial dysfunction in the brain of the senescence-accelerated mouse-prone 8 . Neurochemistry International, 62(5), 595-602. https://doi.org/10.1016/j.neuint.2013.02.014

Farooqui, A.A., Farooqui, T., Madan, A., Ong, J.H.-J. and Ong, W.-Y. (2018). Ayurvedic medicine for the treatment of dementia: mechanistic aspects. Evidence-Based Complementary Alternative Medicine, 2018, $2481076 . \quad$ https:// doi.org/10.1155/2018/2481076

Fazel Nabavi, S., Braidy, N., Habtemariam, S., Sureda, A., Manayi, A. and Mohammad Nabavi, S. (2016). Neuroprotective effects of fisetin in Alzheimer's and Parkinson's Diseases: From chemistry to medicine. Current Topics in Medicinal Chemistry, 16(17), 1910-1915. https:// doi.org/10.2174/1568026616666160204121725

Fricker, R.A., Green, E.L., Jenkins, S.I. and Griffin, S M. (2018). The influence of nicotinamide on health and disease in the central nervous system. International Journal of Tryptophan Research, 11, 1178646918776658. https:// doi.org/10.1177/1178646918776658

Galano, A. (2015). Free radicals induced oxidative stress at a molecular level: the current status, challenges and perspectives of computational chemistry based protocols. Journal of the Mexican Chemical Society, 59(4), 231-262. https://doi.org/10.29356/ jmcs.v59i4.81

Gazal, M., Valente, M.R., Acosta, B.A., Kaufmann, F.N., Braganhol, E., Lencina, C.L., Stefanello, F.M., Ghisleni, G. and Kaster, M.P. (2014). Neuroprotective and antioxidant effects of curcumin in a ketamine-induced model of mania in rats. European Journal of Pharmacology, 724, 132-139. https://doi.org/10.1016/j.ejphar.2013.12.028

Gomes, B.A.Q., Silva, J.P.B., Romeiro, C.F.R., Dos Santos, S.M., Rodrigues, C.A., Gonçalves, P.R., Sakai, J.T., Mendes, P.F.S., Varela, E.L.P. and Monteiro, M.C. (2018). Neuroprotective mechanisms of resveratrol in Alzheimer's disease: role of SIRT1. Oxidative Medicine and Cellular 
Longevity, 2018, $\quad 8152373 . \quad$ https:// doi.org/10.1155/2018/8152373

Guo, Y.J., Dong, S.Y., Cui, X.X., Feng, Y., Liu, T., Yin, M., Kuo, S. H., Tan, E.K., Zhao, W.J. and Wu, Y.C. (2016). Resveratrol alleviates MPTP-induced motor impairments and pathological changes by autophagic degradation of $\alpha$-synuclein via SIRT1-deacetylated LC3. Molecular Nutrition Food Research, 60(10), 2161-2175. https://doi.org/10.1002/mnfr.201600111

Gupta, S.C., Patchva, S., Koh, W. and Aggarwal, B.B. (2012). Discovery of curcumin, a component of golden spice, and its miraculous biological activities. Clinical Experimental Pharmacology Physiology, 39 (3), 283-299. https://doi.org/10.1111/j.14401681.2011.05648.x

Hatami, M., Abdolahi, M., Soveyd, N., Djalali, M., Togha, M. and Honarvar, N.M. (2019). Molecular mechanisms of curcumin in neuroinflammatory disorders: a mini review of current evidences. Endocrine Metabolic Immune Disorders-Drug Targets, 19(3), 247-258. https:// doi.org/10.2174/1871530319666181129103056

Hewlings, S.J. and Kalman, D.S. (2017). Curcumin: a review of its' effects on human health. Foods, 6(10), 92. https://doi.org/10.3390/foods6100092

Höhn, A. and Grune, T. (2013). Lipofuscin: formation, effects and role of macroautophagy. Redox Biology, 1(1), $\quad$ 140-144. https://doi.org/10.1016/ j.redox.2013.01.006

Hsieh, C. (2001). Phase I clinical trial of curcumin, a chemopreventive agent, in patients with high-risk or pre-malignant lesions. Anticancer Research, 21 (2895), e2900.

Huang, S.-S., Lee, M.-C., Liao, Y.-C., Wang, W.-F. and Lai, T.-J. (2012). Caregiver burden associated with behavioral and psychological symptoms of dementia (BPSD) in Taiwanese elderly. Archives of Gerontology, 55(1), 55-59. https://doi.org/10.1016/ j.archger.2011.04.009

Jamwal, R. (2018). Bioavailable curcumin formulations: A review of pharmacokinetic studies in healthy volunteers. Journal of Integrative Medicine, 16(6), 367-374. https://doi.org/10.1016/j.joim.2018.07.001

Jayanarayanan, S., Smijin, S., Peeyush, K., Anju, T. and Paulose, C. (2013). NMDA and AMPA receptor mediated excitotoxicity in cerebral cortex of streptozotocin induced diabetic rat: ameliorating effects of curcumin. Chemico-Biological Interactions, 201(1-3), 39-48. https:// doi.org/10.1016/j.cbi.2012.11.024

Jessica Elizabeth, D.L.T., Gassara, F., Kouassi, A.P., Brar, S.K. and Belkacemi, K. (2017). Spice use in food: Properties and benefits. Critical Reviews in Food Science Nutrition, 57(6), 1078-1088. https:// doi.org/10.1080/10408398.2013.858235

Jiang, H., Tian, X., Guo, Y., Duan, W., Bu, H. and Li, C. (2011). Activation of nuclear factor erythroid 2related factor 2 cytoprotective signaling by curcumin protect primary spinal cord astrocytes against oxidative toxicity. Biological Pharmaceutical Bulletin, 34(8), 1194-1197. https://doi.org/10.1248/ bpb.34.1194

Jurenka, J.S. (2009). Anti-inflammatory properties of curcumin, a major constituent of Curcuma longa: a review of preclinical and clinical research. Alternative Medicine Review, 14(2), 141-153.

Kaplan, H.M., Ok, F. and Demir, E. (2017). Alphalinolenic Acid Attenuates Lipopolysaccharide Induced Cystitis. Pharmacology, 13(6), 649-653. https://doi.org/10.3923/ijp.2017.649.653

Kaur, S., Dhiman, M. and Mantha, A.K. (2018). Ferulic Acid: A Natural Antioxidant with Application Towards Neuroprotection Against Alzheimer's Disease. In Rani, V. and Yadav, U.C.S. (Eds). Functional Food and Human Health, p. 575-586. Singapore: Springer. https://doi.org/10.1007/978-981 -13-1123-9_25

Khan, A., Ali, T., Rehman, S.U., Khan, M.S., Alam, S.I., Ikram, M., Muhammad, T., Saeed, K., Badshah, H. and Kim, M.O. (2018). Neuroprotective effect of quercetin against the detrimental effects of LPS in the adult mouse brain. Frontiers in Pharmacology, 9, 1383. https://doi.org/10.3389/fphar.2018.01383

Kim, C.-S., Choi, H.-S., Joe, Y., Chung, H.T. and Yu, R. (2016). Induction of heme oxygenase-1 with dietary quercetin reduces obesity-induced hepatic inflammation through macrophage phenotype switching. Nutrition Research and Practice, 10(6), 623-628. https://doi.org/10.4162/nrp.2016.10.6.623

Kim, G.H., Kim, J.E., Rhie, S.J. and Yoon, S. (2015). The role of oxidative stress in neurodegenerative diseases. Experimental Neurobiology, 24(4), 325340. https://doi.org/10.5607/en.2015.24.4.325

Kim, Y., You, Y., Yoon, H.-G., Lee, Y.-H., Kim, K., Lee, J., Kim, M.S., Kim, J.-C. and Jun, W.J.F.C. (2014). Hepatoprotective effects of fermented Curcuma longa L. on carbon tetrachloride-induced oxidative stress in rats. Food Chemistry, 151, 148153. https://doi.org/10.1016/j.foodchem.2013.11.058

Kodali, M., Parihar, V.K., Hattiangady, B., Mishra, V., Shuai, B. and Shetty, A.K. (2015). Resveratrol prevents age-related memory and mood dysfunction with increased hippocampal neurogenesis and microvasculature, and reduced glial activation. 
Scientific Reports, 5, 8075. https://doi.org/10.1038/ srep08075

Konar, A., Singh, P. and Thakur, M.K. (2016). Ageassociated cognitive decline: insights into molecular switches and recovery avenues. Aging, 7(2), 121129. https://doi.org/10.14336/AD.2015.1004

Kujawska, M. and Jodynis-Liebert, J. (2018). Polyphenols in Parkinson's disease: A systematic review of in vivo studies. Nutrients, 10(5), 642. https://doi.org/10.3390/nu10050642

Kulkarni, S.K., Bhutani, M.K. and Bishnoi, M. (2008). Antidepressant activity of curcumin: involvement of serotonin and dopamine system. Psychopharmacology, 201, $435 . \quad \mathrm{https} / /$ doi.org/10.1007/s00213-008-1300-y

Kumar, A., Dogra, S. and Prakash, A. (2009). Protective effect of curcumin (Curcuma longa), against aluminium toxicity: Possible behavioral and biochemical alterations in rats. Behavioural Brain Research, 205(2), 384-390. https://doi.org/10.1016/ j.bbr.2009.07.012

Kumar, A. and Singh, A. (2015). A review on Alzheimer's disease pathophysiology and its management: an update. Pharmacological Reports, 67(2), 195-203. https://doi.org/10.1016/ j.pharep.2014.09.004

Kuwatada, J.S., Raja, M. and Sood, P. (2017). Turmeric: A Boon to Oral Health. Internationa Journal of Oral Care Research, 5(4), 338-341. https:// doi.org/10.5005/jp-journals-10051-0128

Lacour, A., Espinosa, A., Louwersheimer, E., Heilmann, S., Hernández, I., Wolfsgruber, S., Fernández, V., Wagner, H., Rosende-Roca, M. and Mauleón, A. (2017). Genome-wide significant risk factors for Alzheimer's disease: role in progression to dementia due to Alzheimer's disease among subjects with mild cognitive impairment. Molecular Psychiatry, 22(1), 153-160. https://doi.org/10.1038/mp.2016.18

Lao, C.D., Ruffin, M.T., Normolle, D., Heath, D.D., Murray, S.I., Bailey, J.M., Boggs, M.E., Crowell, J., Rock, C.L. and Brenner, D.E. (2006). Dose escalation of a curcuminoid formulation. $B M C$ Complementary Alternative Medicine Review, 6(1), 1 -4. https://doi.org/10.1186/1472-6882-6-10

Latif, M.S., Abbas, S., Kormin, F. and Mustafa, M.K. (2019). Green synthesis of plant-mediated metal nanoparticles: The role of polyphenols. Asian Journal of Pharmaceutical and Clinical Research, 12(7), $\quad$ 75-84. ajpcr.2019.v12i7.33211

Lavoie, S., Chen, Y., Dalton, T. P., Gysin, R., Cuénod, M., Steullet, P. and Do, K.Q. (2009). Curcumin, quercetin, and tBHQ modulate glutathione levels in astrocytes and neurons: importance of the glutamate cysteine ligase modifier subunit. Journal of Neurochemistry, 108(6), 1410-1422. https:// doi.org/10.1111/j.1471-4159.2009.05908.x

Lee, J., Giordano, S. and Zhang, J. (2012). Autophagy, mitochondria and oxidative stress: cross-talk and redox signalling. Biochemical Journal, 441(2), 523540. https://doi.org/10.1042/BJ20111451

Lee, W.-H., Loo, C.-Y., Bebawy, M., Luk, F., Mason, R. S. and Rohanizadeh, R. (2013). Curcumin and its derivatives: their application in neuropharmacology and neuroscience in the 21st century. Current Neuropharmacology, 11(4), 338-378. https:// doi.org/10.2174/1570159X11311040002

Legdeur, N., Heymans, M., Comijs, H., Huisman, M., Maier, A. and Visser, P. (2018). Age dependency of risk factors for cognitive decline. BMC Geriatrics, 18(1), 187. https://doi.org/10.1186/s12877-018-0876 $-2$

Li, W., Suwanwela, N.C. and Patumraj, S. (2017). Curcumin prevents reperfusion injury following ischemic stroke in rats via inhibition of NF- $\kappa B$, ICAM-1, MMP-9 and caspase-3 expression. Molecular Medicine Reports, 16(4), 4710-4720. https://doi.org/10.3892/mmr.2017.7205

Lim, C.S. and Han, J.-S. (2018). The antioxidant xanthorrhizol prevents amyloid- $\beta$-induced oxidative modification and inactivation of neprilysin. Bioscience Reports, 38(1), BSR20171611. https:// doi.org/10.1042/BSR20171611

Lim, G.P., Chu, T., Yang, F., Beech, W., Frautschy, S.A. and Cole, G.M. (2001). The curry spice curcumin reduces oxidative damage and amyloid pathology in an Alzheimer transgenic mouse. Journal of Neuroscience, 21(21), 8370-8377. https:// doi.org/10.1523/JNEUROSCI.21-21-08370.2001

Liu, W., Zhai, Y., Heng, X., Che, F.Y., Chen, W., Sun, D. and Zhai, G. (2016). Oral bioavailability of curcumin: problems and advancements. Journal of Drug Targeting, 24(8), 694-702. https:// doi.org/10.3109/1061186X.2016.1157883

Liu, Z., Zhou, T., Ziegler, A.C., Dimitrion, P. and Zuo, L. (2017). Oxidative stress in neurodegenerative diseases: from molecular mechanisms to clinical applications. Oxidative Medicine and Cellular Longevity, 2017, 252596. https:// doi.org/10.1155/2017/2525967

Lloret, A., Esteve, D., Monllor, P., Cervera-Ferri, A. and Lloret, A. (2019). The effectiveness of vitamin E treatment in Alzheimer's disease. International 
Journal of Molecular Sciences, 20(4), 879. https:// doi.org/10.3390/ijms20040879

Llurba-Montesino, N., Kaiser, M., Brun, R. and Schmidt, T. (2015). Search for antiprotozoal activity in herbal medicinal preparations; new natural leads against neglected tropical diseases. Molecules, 20(8), 1411814138. https://doi.org/10.3390/molecules200814118

Lopresti, A.L., Maes, M., Maker, G.L., Hood, S.D. and Drummond, P.D. (2014). Curcumin for the treatment of major depression: a randomised, double-blind, placebo controlled study. Journal of Affective Disorders, 167, 368-375. https://doi.org/10.1016/ j.jad.2014.06.001

Luchena, C., Zuazo-Ibarra, J., Alberdi, E., Matute, C. and Capetillo-Zarate, E. (2018). Contribution of neurons and glial cells to complement-mediated synapse removal during development, aging and in Alzheimer's disease. Mediators of Inflammation, 2018, 2530414.

https:// doi.org/10.1155/2018/2530414

Luo, Y., Hattori, A., Munoz, J., Qin, Z.-H. and Roth, G.S. (1999). Intrastriatal dopamine injection induces apoptosis through oxidation-involved activation of transcription factors $\mathrm{AP}-1$ and $\mathrm{NF}-\mathrm{\kappa B}$ in rats. Molecular Pharmacology, 56(2), 254-264. https:// doi.org/10.1124/mol.56.2.254

Magalingam, K.B., Radhakrishnan, A.K. and Haleagrahara, N. (2015). Protective mechanisms of flavonoids in Parkinson's disease. Oxidative Medicine and Cellular Longevity, 2015, 314560. https://doi.org/10.1155/2015/314560

Maiti, P. and Dunbar, G.L. (2018). Use of curcumin, a natural polyphenol for targeting molecular pathways in treating age-related neurodegenerative diseases. International Journal of Molecular Sciences, 19(6), 1637. https://doi.org/10.3390/ijms19061637

Maiti, P., Manna, J. and Dunbar, G.L. (2017). Current understanding of the molecular mechanisms in Parkinson's disease: targets for potential treatments. Translational Neurodegeneration, 6(1), 28. https:// doi.org/10.1186/s40035-017-0099-z

Man Anh, H., Linh, D.M., My Dung, V. and Thi Phuong Thao, D. (2019). Evaluating dose-and timedependent effects of vitamin $\mathrm{c}$ treatment on a parkinson's disease fly model. Parkinson's Disease, 2019, $9720546 . \quad$ https:// doi.org/10.1155/2019/9720546

Mazzio, E.A., Close, F. and Soliman, K.F. (2011). The biochemical and cellular basis for nutraceutical strategies to attenuate neurodegeneration in Parkinson's disease. International Journal of
Molecular Sciences, 12(1), 506-569. https:// doi.org/10.3390/ijms 12010506

McMackin, R., Muthuraman, M., Groppa, S., Babiloni, C., Taylor, J.-P., Kiernan, M.C., Nasseroleslami, B. and Hardiman, O. (2019). Measuring network disruption in neurodegenerative diseases: New approaches using signal analysis. Journal of Neurology, Neurosurgery and Psychiatry, 90(9), 1011-1020. https://doi.org/10.1136/jnnp-2018319581

Mecocci, P., Mariani, E., Cornacchiola, V. and Polidori, M. (2004). Antioxidants for the treatment of mild cognitive impairment. Neurological research, 26(5), 598-602. doi.org/10.1179/016164104225017659

https://

Mehlhorn, R.J. and Cole, G. (1985). The free radical theory of aging: a critical review. Advances in Free Radical Biology Medicine, 1(1), 165-223. https:// doi.org/10.1016/8755-9668(85)90007-9

Melki, R. (2015). Role of different alpha-synuclein strains in synucleinopathies, similarities with other neurodegenerative diseases. Journal of Parkinson's Disease, 5(2), 217-227. https://doi.org/10.3233/JPD150543

Mishra, S. and Palanivelu, K. (2008). The effect of curcumin (turmeric) on Alzheimer's disease: An overview. Annals of Indian Academy of Neurology, 11(1), 13-19. https://doi.org/10.4103/09722327.40220

Naik, S.R., Thakare, V.N. and Patil, S.R. (2011). Protective effect of curcumin on experimentally induced inflammation, hepatotoxicity and cardiotoxicity in rats: evidence of its antioxidant property. Experimental Toxicologic Pathology, 63 (5), 419-431. https://doi.org/10.1016/ j.etp. 2010.03 .001

Nakayama, H., Tsuge, N., Sawada, H., Masamura, N., Yamada, S., Satomi, S. and Higashi, Y. (2014). A single consumption of curry improved postprandial endothelial function in healthy male subjects: a randomized, controlled crossover trial. Nutrition Journal, 13(1), 67. https://doi.org/10.1186/14752891-13-67

Natarajan, S., Shunmugiah, K.P. and Kasi, P.D. (2013). Plants traditionally used in age-related brain disorders (dementia): an ethanopharmacological survey. Pharmaceutical Biology, 51(4), 492-523. https://doi.org/10.3109/13880209.2012.738423

Nazari, Q.A., Takada-Takatori, Y., Hashimoto, T., Imaizumi, A., Izumi, Y., Akaike, A. and Kume, T. (2014). Potential protective effect of highly bioavailable curcumin on an oxidative stress model 
induced by microinjection of sodium nitroprusside in mice brain. Food Function, 5(5), 984-989. https:// doi.org/10.1039/C4FO00009A

Nedeljković, P., Dacić, S., Kovačević, M., Peković, S., Vučević, D. and Božić-Nedeljković, B. (2018). Vitamin B complex as a potential therapeutical modality in combating peripheral nerve injury. Acta Medica Medianae, 57(2), 85-91. https:// doi.org/10.5633/amm.2018.0214

Ng, T.-P., Chiam, P.-C., Lee, T., Chua, H.-C., Lim, L. and Kua, E.-H. (2006). Curry consumption and cognitive function in the elderly. American Journal of Epidemiology, 164(9), 898-906. https:// doi.org/10.1093/aje/kwj267

Nour, A.H., Khan, M., Sulaiman, A.Z., Batool, T., Nour, A.H., Khan, M.M. and Kormin, F. (2014). In vitro anti-acetylcholinesterase and antioxidant activity of selected Malaysian plants. Asian Journal of Pharmaceutical Clinical Research, 7(3), 93-97.

Novaes, J T., Lillico, R., Sayre, C.L., Nagabushanam, K., Majeed, M., Chen, Y., Ho, E.A., Oliveira, A.L.D. P., Martinez, S.E. and Alrushaid, S. (2017). Disposition, metabolism and histone deacetylase and acetyltransferase inhibition activity of tetrahydrocurcumin and other curcuminoids. Pharmaceutics, 9(4), 45. https://doi.org/10.3390/ pharmaceutics 9040045

Ortiz-Ortiz, M.A., Morán, J.M., Ruiz-Mesa, L.M., NisoSantano, M., Bravo-SanPedro, J.M., GómezSánchez, R., González-Polo, R.A. and Fuentes, J.M. (2010). Curcumin exposure induces expression of the Parkinson's disease-associated leucine-rich repeat kinase 2 (LRRK2) in rat mesencephalic cells. Neuroscience Letters, 468(2), 120-124. https:// doi.org/10.1016/j.neulet.2009.10.081

Ovais, M., Zia, N., Ahmad, I., Khalil, A.T., Raza, A., Ayaz, M., Sadiq, A., Ullah, F. and Shinwari, Z.K. (2018). Phyto-Therapeutic and nanomedicinal approaches to cure alzheimer's disease: present status and future opportunities. Frontiers in Aging Neuroscience, 10, 284. https://doi.org/10.3389/ fnagi.2018.00284

Palomera-Avalos, V., Griñán-Ferré, C., Izquierdo, V., Camins, A., Sanfeliu, C. and Pallàs, M. (2017). Metabolic stress induces cognitive disturbances and inflammation in aged mice: protective role of resveratrol. Rejuvenation Research, 20(3), 202-217. https://doi.org/10.1089/rej.2016.1885

Perkins, S., Verschoyle, R.D., Hill, K., Parveen, I., Threadgill, M.D., Sharma, R.A., Williams, M.L., Steward, W.P. and Gescher, A.J. (2002). Chemopreventive efficacy and pharmacokinetics of curcumin in the $\mathrm{min} /+$ mouse, a model of familial adenomatous polyposis. Cancer Epidemiology and Prevention Biomarkers, 11(6), 535-540.

Phom, L., Achumi, B., Alone, D.P. and Yenisetti, S.C. (2014). Curcumin's neuroprotective efficacy in Drosophila model of idiopathic Parkinson's disease is phase specific: implication of its therapeutic effectiveness. Rejuvenation Research, 17(6), 481489. https://doi.org/10.1089/rej.2014.1591

Prasad, S., Tyagi, A.K. and Aggarwal, B.B. (2014). Recent developments in delivery, bioavailability, absorption and metabolism of curcumin: the golden pigment from golden spice. Cancer Research and Treatment, 46(1), 2-18. https://doi.org/10.4143/ crt.2014.46.1.2

Prorok, T., Jana, M., Patel, D. and Pahan, K. (2019). Cinnamic Acid Protects the Nigrostriatum in a Mouse Model of Parkinson's Disease via Peroxisome Proliferator-Activated Receptor $\alpha$ Neurochemical Research, 44(4), 751-762. https:// doi.org/10.1007/s11064-018-02705-0

Qabaha, K., Abu-Lafi, S. and Al-Rimawi, F. (2017). Anti -inflammatory Activities of Ethanolic Extracts of curcuma Longa (Turmeric) and cinnamon (Cinnamomum verum). Journal of Food and Nutrition Research, 5(9), 668-673.

Randino, R., Grimaldi, M., Persico, M., De Santis, A., Cini, E., Cabri, W., Riva, A., D’Errico, G., Fattorusso, C., D'Ursi, A.M. and Rodriquez, M. (2016). Investigating the neuroprotective effects of turmeric extract: structural interactions of $\beta$-amyloid peptide with single curcuminoids. Scientific Reports, 6, 38846. https://doi.org/10.1038/srep38846

Ravindranath, V. and Chandrasekhara, N. (1980). Absorption and tissue distribution of curcumin in rats. Toxicology, 16(3), 259-265. https:// doi.org/10.1016/0300-483X(80)90122-5

Reddy, P.H., Manczak, M., Yin, X., Grady, M.C., Mitchell, A., Tonk, S., Kuruva, C.S., Bhatti, J.S., Kandimalla, R. and Vijayan, M. (2018). Protective effects of Indian spice curcumin against amyloid- $\beta$ in Alzheimer's disease. Journal of Alzheimer's Disease, 61(3), 843-866. https://doi.org/10.3233/ JAD-170512

Robinson, L., Tang, E. and Taylor, J.-P. (2015). Dementia: timely diagnosis and early intervention. BMJ, 350, h3029. https://doi.org/10.1136/bmj.h3029

Saha, L., Chakrabarti, A., Kumari, S., Bhatia, A. and Banerjee, D. (2016). Antiapoptotic and neuroprotective role of Curcumin in Pentylenetetrazole (PTZ) induced kindling model in rat. Indian Journal of Experimental Biology, 52(2), 133-141. 
Samy, D.M., Ismail, C.A., Nassra, R.A., Zeitoun, T.M. and Nomair, A.M. (2016). Downstream modulation of extrinsic apoptotic pathway in streptozotocininduced Alzheimer's dementia in rats: Erythropoietin versus curcumin. European Journal of Pharmacology, 770, 52-60. https://doi.org/10.1016/ j.ejphar.2015.11.046

Sankar, P., Telang, A.G., Kalaivanan, R., Karunakaran, V., Suresh, S. and Kesavan, M. (2016). Oral nanoparticulate curcumin combating arsenic-induced oxidative damage in kidney and brain of rats. Toxicology and Industrial Health, 32(3), 410-421. https://doi.org/10.1177/0748233713498455

Selvi, N.M.K., Sridhar, M., Swaminathan, R. and Sripradha, R. (2015). Efficacy of turmeric as adjuvant therapy in type 2 diabetic patients. Indian Journal of Clinical Biochemistry, 30(2), 180-186. https://doi.org/10.1007/s12291-014-0436-2

Sharma, C., Suhalka, P., Sukhwal, P., Jaiswal, N. and Bhatnagar, M. (2014). Curcumin attenuates neurotoxicity induced by fluoride: an in vivo evidence. Pharmacognosy Magazine, 10(37), 61-65. https://doi.org/10.4103/0973-1296.126663

Shen, Y., Ye, B., Chen, P., Wang, Q., Fan, C., Shu, Y. and Xiang, M. (2018). Cognitive decline, dementia, alzheimer's disease and presbycusis: examination of the possible molecular mechanism. Frontiers in Neuroscience, 12, 394. https://doi.org/10.3389/ fnins.2018.00394

Gadad, B.S., Subramanya, P.K., Pullabhatla, S., Shantharam, I.S. and Rao, K.S. (2012). Curcuminglucoside, a novel synthetic derivative of curcumin, inhibits $\alpha$-synuclein oligomer formation: relevance to Parkinson's disease. Current Pharmaceutical Design, 18(1), 76-84. https:// doi.org/10.2174/138161212798919093

Singh, P., Yasir, M., Hazarika, R., Sugunan, S. and Shrivastava, R. (2017). A review on venom enzymes neutralizing ability of secondary metabolites from medicinal plants. Journal of Pharmacopuncture, 20 (3), 173-178. https://doi.org/10.3831/ KPI.2017.20.020

Siviero, A., Gallo, E., Maggini, V., Gori, L., Mugelli, A., Firenzuoli, F. and Vannacci, A. (2015). Curcumin, a golden spice with a low bioavailability. Journal of Herbal Medicine, 5(2), 57-70. https:// doi.org/10.1016/j.hermed.2015.03.001

Song, S., Nie, Q., Li, Z. and Du, G. (2016). Curcumin improves neurofunctions of 6-OHDA-induced parkinsonian rats. Pathology-Research and Practice, 212(4), 247-251. https://doi.org/10.1016/ j.prp.2015.11.012
Spagnuolo, C., Napolitano, M., Tedesco, I., Moccia, S., Milito, A. and Luigi Russo, G. (2016). Neuroprotective role of natural polyphenols. Current Topics in Medicinal Chemistry, 16(17), 1943-1950. https://

doi.org/10.2174/1568026616666160204122449

Subramaniam, S.R. and Chesselet, M.-F. (2013). Mitochondrial dysfunction and oxidative stress in Parkinson's disease. Progress in Neurobiology, 106107, 17-32. https://doi.org/10.1016/ j.pneurobio.2013.04.004

Suryanarayana, P., Satyanarayana, A., Balakrishna, N., Kumar, P.U. and Reddy, G.B. (2007). Effect of turmeric and curcumin on oxidative stress and antioxidant enzymes in streptozotocin-induced diabetic rat. Medical Science Monitor, 13(12), BR286-BR292.

Tamagno, E., Parola, M., Bardini, P., Piccini, A., Borghi, R., Guglielmotto, M., Santoro, G., Davit, A., Danni, O. and Smith, M. (2005). $\beta$-Site APP cleaving enzyme up-regulation induced by 4-hydroxynonenal is mediated by stress-activated protein kinases pathways. Journal of Neurochemistry, 92(3), 628636.

4159.2004.02895.x

https://doi.org/10.1111/j.1471-

Tang, M. and Taghibiglou, C. (2017). The mechanisms of action of curcumin in Alzheimer's disease. Journal of Alzheimer's Disease, 58(4), 1003-1016. https://doi.org/10.3233/JAD-170188

Vaughn, A.R., Branum, A. and Sivamani, R.K. (2016). Effects of turmeric (Curcuma longa) on skin health: a systematic review of the clinical evidence. Phytotherapy Research, 30(8), 1243-1264. https:// doi.org/10.1002/ptr.5640

Vemuri, S.K., Banala, R.R., Subbaiah, G., Srivastava, S.K., Reddy, A.G. and Malarvili, T. (2017). Anticancer potential of a mix of natural extracts of turmeric, ginger and garlic: A cell-based study. Egyptian Journal of Basic and Applied Sciences, 4 (4), 332-344. https://doi.org/10.1016/ j.ejbas.2017.07.005

Wang, J., Zhang, Y. and Du, S. (2012). The protective effect of curcumin on $A \beta$ induced aberrant cell cycle reentry on primary cultured rat cortical neurons. European Review for Medical and Pharmacological Sciences, 16(4), 445-454.

Wang, Z., Zhang, Q., Yuan, L., Wang, S., Liu, L., Yang, X., Li, G. and Liu, D. (2014). The effects of curcumin on depressive-like behavior in mice after lipopolysaccharide administration. Behavioural Brain Research, 274, 282-290. https:// doi.org/10.1016/j.bbr.2014.08.018 
Waseem, M. and Parvez, S. (2016). Neuroprotective activities of curcumin and quercetin with potential relevance to mitochondrial dysfunction induced by oxaliplatin. Protoplasma, 253(2), 417-430. https:// doi.org/10.1007/s00709-015-0821-6

Weis, S., Sonnberger, M., Dunzinger, A., Voglmayr, E., Aichholzer, M., Kleiser, R. and Strasser, P. (2019). Neurodegenerative Diseases: Motor Neuron Diseases. In Imaging Brain Diseases, p. 1037-1057. Vienna: Springer. https://doi.org/10.1007/978-37091-1544-2_39

Wong, C.B., Kobayashi, Y. and Xiao, J.-Z. (2018). Probiotics for Preventing Cognitive Impairment in Alzheimer's Disease. In Evrensel, A. (Ed). Gut Microbiota-Brain Axis, p. 85-104. London, UK: IntechOpen.

Yaari, R., Kumar, S. and Tariot, P.N. (2008). Noncholinergic drug development for Alzheimer's disease. Expert Opinion on Drug Discovery, 3(7), 745-760. https://doi.org/10.1517/17460441.3.7.745

Yang, X., Jiang, H. and Shi, Y. (2017). Upregulation of heme oxygenase-1 expression by curcumin conferring protection from hydrogen peroxideinduced apoptosis in H9c2 cardiomyoblasts. Cell and Bioscience Reports, 7, 20. https://doi.org/10.1186/ s13578-017-0146-6

Yao, E.C. and Xue, L. (2014). Therapeutic effects of curcumin on Alzheimer's disease. Advances in Alzheimer's Disease, 3(4), 145-159. https:// doi.org/10.4236/aad.2014.34014

Ye, J. and Zhang, Y. (2012). Curcumin protects against intracellular amyloid toxicity in rat primary neurons. International Journal of Clinical Experimental Medicine 5(1), 44-49.

Yu, H. and Huang, Q. (2012). Improving the oral bioavailability of curcumin using novel organogelbased nanoemulsions. Journal of Agricultural Food Chemistry, 60(21), 5373-5379. https:// doi.org/10.1021/jf300609p

Yuliani, S., Mustofa and Partadiredja, G. (2019). The neuroprotective effects of an ethanolic turmeric (Curcuma longa L.) extract against trimethyltininduced oxidative stress in rats. Nutritional Neuroscience, 22(11), 797-804. https:// doi.org/10.1080/1028415X.2018.1447267

Zhang, C., Browne, A., Child, D. and Tanzi, R.E. (2010). Curcumin decreases amyloid- $\beta$ peptide levels by attenuating the maturation of amyloid- $\beta$ precursor protein. Journal of Biological Chemistry, 285(37), 28472-28480. https://doi.org/10.1074/ jbc.M110.133520
Zhang, J. (2013). Autophagy and mitophagy in cellular damage control. Redox Biology, 1(1), 19-23. https:// doi.org/10.1016/j.redox.2012.11.008

Zhang, L.J., Wu, C.F., Meng, X.L., Yuan, D., Cai, X.D., Wang, Q.L. and Yang, J.Y. (2008). Comparison of inhibitory potency of three different curcuminoid pigments on nitric oxide and tumor necrosis factor production of rat primary microglia induced by lipopolysaccharide. Neuroscience Letters, 447(1), 48 -53. https://doi.org/10.1016/j.neulet.2008.09.067

Zhang, T., Han, Y., Wang, J., Hou, D., Deng, H., Deng, Y.L. and Song, Z. (2018). Comparative epidemiological investigation of Alzheimer's disease and colorectal cancer: the possible role of gastrointestinal conditions in the pathogenesis of AD. Frontiers in Aging Neuroscience, 10, 176. https://doi.org/10.3389/fnagi.2018.00176

Zhao, B., Li, X., He, R., Cheng, S. and Wenjuan, X. (1989). Scavenging effect of extracts of green tea and natural antioxidants on active oxygen radicals. Cell Biophysics, 14(2), 175-185. https:// doi.org/10.1007/BF02797132

Zhou, X., Li, Y., Shi, X. and Ma, C. (2016). An overview on therapeutics attenuating amyloid $\beta$ level in Alzheimer's disease: Targeting neurotransmission, inflammation, oxidative stress and enhanced cholesterol levels. American Journal of Translational Research, 8(2), 246-269.

Ziegler-Waldkirch, S. and Meyer-Luehmann, M. (2018). The role of glial cells and synapse loss in mouse models of Alzheimer's disease. Frontiers in Cellular Neuroscience, 12, 473. https://doi.org/10.3389/ fncel.2018.00473 